
\title{
28 Research Soure \\ HbA1c and Blood Pressure Levels in Type 2 Diabetes: How Many Patients are on Target?
}

Camila Bergonsi de Farias

Universidade Federal do Rio Grande do Sul

Themis Zelmanovitz

Universidade Federal do Rio Grande do Sul

Sabrina Coelli

Universidade Federal do Rio Grande do Sul

Fabíola Satler

Hospital de Clinicas de Porto Alegre

Camila Kümmel Duarte

Universidade Federal do Rio Grande do Sul

Letícia Brondani

Universidade Federal do Rio Grande do Sul

Sandra Pinho Silveiro ( $\nabla$ ssilveiro@hcpa.edu.br)

\section{Research}

Keywords: type 2 diabetes, diabetes mellitus, arterial blood pressure, glycated hemoglobin, target, HbA1c

Posted Date: March 5th, 2020

DOI: https://doi.org/10.21203/rs.3.rs-16091/v1

License: (c) (i) This work is licensed under a Creative Commons Attribution 4.0 International License.

Read Full License

Version of Record: A version of this preprint was published at Canadian Journal of Diabetes on June 1st, 2021. See the published version at https://doi.org/10.1016/j.jcjd.2020.10.002. 


\section{Abstract}

Background: Achieving HbA1c and blood pressure targets is an important strategy for preventing chronic vascular complications in diabetes. The aim of this paper was to determine the proportion of type 2 diabetes patients who meet the recommended $\mathrm{HbA} 1 \mathrm{c}$ and arterial blood pressure targets and the determinants of failure to do so.

Methods: A cross-sectional study was conducted in an outpatient endocrine clinic at a university hospital. $\mathrm{HbA1c}$ was measured with a certified HPLC method, with a goal of $7 \%$, except for patients with advanced chronic complications where $8 \%$ was the goal. Blood pressure was measured with a validated device after a 5-minute rest, and the overall expected target was $140 / 90 \mathrm{mmHg}$.

Results: A total of 602 type 2 diabetes patients were analyzed: $62 \%$ were female, $14 \%$ self-reported as black, the mean age was $63 \pm 11$ years, the mean diabetes duration was $17 \pm 9$ years, and the median (IQR) HbA1c was 8.0\% (7.0-9.5\%). Macrovascular disease was present in 198 (33\%) patients, diabetic retinopathy in 283 (47\%), peripheral neuropathy in 258 (43\%) and diabetes kidney disease in 337 (56\%). Regarding metabolic control, 403 (67\%) patients were not at the adjusted target $\mathrm{HbA} 1 \mathrm{c}$ level, and the main determinants of poor glycemic control were female gender, black skin color, younger age, and insulin use. Regarding blood pressure, 348 (58\%) patients were not at the recommended targets, and a more advanced age was the main associated factor.

Conclusions: Since more than half of Brazilian type 2 diabetes outpatients do not meet the recommended $\mathrm{HbA} 1 \mathrm{c}$ and blood pressure target values, there is a major call to overcome therapeutic inertia and treat to target each individual patient. Female, black and younger individuals seem to be associated with a worse glycemic profile.

\section{Background}

Diabetes mellitus (DM) is one of the most prevalent chronic diseases, with alarming rates in a number of countries. According to the International Diabetes Federation, in 2019 the global prevalence of DM was 463 million adults and estimated to reach 700 million by 2045, an increase of $51 \%$ (1). Brazil is the fifth leading country in diabetes cases, with a prevalence of 16.8 million adults (1). One of the first Brazilian multicenter studies to evaluate the prevalence of DM in adults was conducted between 1986 and 1988 (2). In a sample of approximately 22,000 individuals aged 30-69 years, the occurrence of type 2 diabetes was around $8 \%$, similar to that of more developed countries (2). A further Brazilian study observed an increase in self-reported DM from 3.3\% in 1998 to $5.3 \%$ in 2008 (3). The prevalence seems to be rising, as indicated in the baseline data of a Brazilian cohort of 15,000 civil servants aged 35-74 years (the ELSA study): the prevalence of type 2 diabetes between $2008-2010$ was $19.7 \%$ (4).

Global mortality attributable to DM has been estimated at 5 million people aged between 20 and 99 years (5). Cardiovascular disease is the most common cause of death among diabetic patients, along with endstage renal disease, this last comprising $20-40 \%$ of these patients $(5,6)$. The most important 
interventions for reducing the onset and/or progression of all diabetic chronic complications are the appropriate control of blood pressure and glucose levels, besides beneficial specific drug therapies, such as renin-angiotensin-aldosterone blockers, glucagon-like peptide 1 receptor agonists and sodium-glucose cotransporter 2 inhibitors (7).

Glycemic management is primarily assessed with the $\mathrm{HbA1C}$ test, which was the chosen parameter in clinical trials when studying the benefits of improved glycemic control. According to 2020 ADA guidelines, an $\mathrm{HbA} 1 \mathrm{c}$ target of $<7 \%$ is a reasonable goal for most adults, while a more restrictive target of $<6.5 \%$ is indicated for patients at lower risk of hypoglycemia $(8,9)$. On the other hand, a higher goal of $8 \%$ is reserved for patients with advanced diabetes complications, history of severe hypoglycemia, limited life expectancy or extensive comorbid conditions (8).

According to the Global Diabetes Plan, the three essential components of diabetes care are treatment and clinical monitoring to achieve glycemic and metabolic control, self-management education and support, and prevention and management of complications (10). Maintaining adequate glycemic and blood pressure control is the most effective treatment for the management and prevention of chronic complications.

The aim of this study was to investigate the proportion of type 2 diabetes patients who meet the target $\mathrm{HbA} 1 \mathrm{c}$ and arterial blood pressure levels and to determine the factors associated with the failure to do so.

\section{Methods}

\section{Patients}

This cross-sectional study evaluated 602 type 2 diabetes patients consecutively examined at the outpatient endocrinology clinic of a university hospital (Hospital de Clínicas de Porto Alegre). Type 2 diabetes was defined as DM diagnosed after 30 years of age, with no prior ketoacidosis and no insulin used for the first 5 years after diagnosis. In doubtful cases, it was confirmed by negative anti-GAD antibodies and elevated C-peptide levels.

\section{Methods}

Data on age, skin color, diabetes duration, and current medications were recorded. DM treatment was classified as diet alone or diet plus oral agents, or both in combination with insulin. The patients' weight and height were measured while shoeless and wearing light clothing, and body mass index (BMI) was calculated based on these measurements (weight/height ${ }^{2} ; \mathrm{kg} / \mathrm{m}^{2}$ ). Blood pressure was measured after a 5-minute rest using a validated Omron device.

\section{Laboratory evaluation}

$\mathrm{HbA1c}$ was measured with certified high-performance liquid chromatography, glucose was measured with the hexokinase method, and total cholesterol, HDL and triglycerides were measured with enzymatic 
colorimetric methods. LDL was calculated with the Friedewald equation. Serum creatinine was measured with the compensated Jaffe method, and the glomerular filtration rate (GFR) was estimated with the Chronic Kidney Disease Epidemiology Collaboration (CKD-EPI) Eq. (11). Urinary albumin excretion (UAE) was measured twice in a random sample using immunoturbidimetry.

\section{Assessment of diabetic chronic complications}

Diabetes kidney disease (DKD) was defined as a low estimated GFR $\left(<60 \mathrm{~mL} / \mathrm{min} / 1.73 \mathrm{~m}^{2}\right)$ and/or UAE $>14 \mathrm{mg} / \mathrm{L}(6,12)$. Diabetic retinopathy was evaluated by direct fundoscopy. Peripheral neuropathy was defined as a lack of sensitivity in at least one point in the $10 \mathrm{~g}$-monofilament test or as the presence of symptoms. Peripheral arterial disease was defined as lack of a palpable lower-limb pulse. Cardiovascular disease was determined through angina symptoms, ischemia by myocardial scintigraphy, prior myocardial infarction or prior coronary revascularization surgery. Cerebrovascular disease was determined through prior report or sequelae upon physical examination.

\section{Therapeutic targets}

The $\mathrm{HbA} 1 \mathrm{c}$ target was defined according to international guidelines as $<7 \%$, whereas for patients with advanced kidney disease (defined herein as GFR $<60 \mathrm{~mL} / \mathrm{min} / 1.73 \mathrm{~m}^{2}$ ) and ischemic heart disease the target was set at $<8 \%(8,13)$. For blood pressure, the targets were $<130 \mathrm{mmHg}$ of systolic and $<$ $80 \mathrm{mmHg}$ of diastolic blood pressure for patients with high cardiovascular risk (defined as existing atherosclerotic cardiovascular disease and/or DKD) and $<140 / 90$ for the remaining patients $(5,14)$.

\section{Statistical analyses}

The results were expressed as mean $\pm S D$, cases (\%) or median (interquartile range). In univariate analyses, continuous variables were analyzed with a t-test and dichotomous variables were analyzed with the chi-square test. The prevalence ratio (PR) and $95 \% \mathrm{Cl}$ were obtained by Poisson regression with robust variance to determine the association of different factors with uncontrolled $\mathrm{HbA} 1 \mathrm{c}$ and blood pressure (dependent variables). Statistical analyses were carried out in SPSS V.18.0. P-values $<0.05$ were considered statistically significant.

\section{Results}

A total of 602 type 2 diabetes patients were analyzed: 374 (62\%) were female, the mean age was $63 \pm 11$ years, the mean DM duration was $17 \pm 9$ years and the median (IQR) HbA1c level was 8.0\% (7.0-9.5\%); 56 (9.3\%) were smokers, 84 (14\%) self-reported their skin color as black and $540(91 \%)$ had arterial hypertension.

Regarding diabetes complications, 197 (33\%) had macrovascular disease, while microvascular complications included 334 (56\%) patients with diabetes kidney disease, 258 (43\%) with peripheral neuropathy and 283 (47\%) with diabetic retinopathy (Fig. 1). 
Regarding glycemic control, 403 (67\%) patients were not at the target HbA1c level after individualizing goals (as defined in the methods section). This group was younger with longer disease duration and included more women, blacks and insulin users. The uncontrolled group also had higher serum cholesterol and triglyceride levels and less macrovascular disease than the well-controlled group (Table 1). Poisson multivariable regression with robust variance confirmed advanced age, female gender, black skin color and insulin use as independent factors associated with uncontrolled HbA1c (Table 2).

To understand why women were more likely to have higher HbA1c levels than men, we stratified the results by gender (Table 3). Age remained significantly lower and insulin use higher in uncontrolled patients in both genders. However, having black skin color and a longer duration of the disease was more prevalent only among off target women, while total cholesterol was higher only in men.

Table 4 shows the clinical and laboratory characteristics of type 2 diabetes patients according to blood pressure target. A total of 348 (58\%) patients, even after adjusting for specific scenarios, were not at the recommended goals. The uncontrolled group had a higher age, but $\mathrm{HbA} 1 \mathrm{c}$, lipid profile and insulin use did not differ between the groups. Regarding the number of anti-hypertensive agents, $46 \%$ of the patients needed at least 3 medications to reach the target $(p<0.001)$. The uncontrolled blood pressure group had a higher proportion of macrovascular disease and DKD. In the multivariable analysis, higher age and the use of three or more anti-hypertensive medications remained significantly related to higher blood pressure (Table 2). 
Table 1

Clinical and laboratory characteristics of type 2 diabetes patients according to $\mathrm{HbA1c}$ values.

\begin{tabular}{|llll|}
\hline & \multicolumn{2}{l}{ HbA1c target } & \multirow{2}{*}{ P-value } \\
\cline { 2 - 3 } & Achieved & Not achieved & \\
\cline { 2 - 3 } & $\mathrm{N}=199$ & $\mathrm{~N}=403$ & \\
\hline Age (years) & $65 \pm 10$ & $62 \pm 11$ & $<0.001$ \\
\hline Female & $100(51)$ & $273(68)$ & $<0.001$ \\
\hline White & $182(92)$ & $336(83)$ & 0.01 \\
\hline Smokers & $18(9)$ & $38(9.5)$ & 0.97 \\
\hline BMI (kg/m²) & $30 \pm 6$ & $31 \pm 5$ & 0.068 \\
\hline Diabetes duration (years) & $16 \pm 10$ & $18 \pm 9$ & 0.013 \\
\hline Insulin use & $101(51)$ & $314(78)$ & $<0.001$ \\
\hline SBP (mmHg) & $136 \pm 20$ & $135 \pm 20$ & 0.708 \\
\hline DBP (mmHg) & $79 \pm 11$ & $78 \pm 12$ & 0.720 \\
\hline HbA1c (\%) & $6.7(6.1-7.4)$ & $8.9(8.0-10.0)$ & by design \\
\hline Fasting plasma glucose (mg/dL) & $123 \pm 43$ & $177 \pm 79$ & $<0.001$ \\
\hline Total cholesterol (mg/dL) & $163 \pm 44$ & $173 \pm 43$ & 0.006 \\
\hline Triglycerides (mg/dL) & $134(97-190)$ & $151(99-224)$ & 0.033 \\
\hline Diabetes kidney disease & $110(55)$ & $226(56)$ & 0.814 \\
\hline Diabetic retinopathy & $91(46)$ & $192(48)$ & 0.750 \\
\hline Peripheral neuropathy & $86(43)$ & $173(43)$ & 0.979 \\
\hline Macrovascular disease & $98(49)$ & $100(25)$ & $<0.001$ \\
\hline
\end{tabular}

Data presented as mean \pm SD, median (interquartile range) or number of cases (\%).

$P$ value was calculated by $X^{2}$ or independent samples t-test.

BMI: body mass index; SBP: systolic blood pressure, DBP: diastolic blood pressure. 
Table 2

Poisson regression with robust variance with target $\mathrm{HbA} 1 \mathrm{c}$ and target blood pressure as dependent variables.

\begin{tabular}{|c|c|c|c|c|}
\hline \multicolumn{5}{|l|}{ Target HbA1c } \\
\hline & \multirow[t]{2}{*}{ PR } & \multicolumn{2}{|l|}{$95 \% \mathrm{Cl}$} & \multirow[t]{2}{*}{ P-value } \\
\hline & & Lower & Upper & \\
\hline Skin color (black) & 1.156 & 1.009 & 1.324 & 0.036 \\
\hline Age & 0.989 & 0.984 & 0.995 & $<0.001$ \\
\hline Insulin use & 1.491 & 1.268 & 1.753 & $<0.001$ \\
\hline Gender (female) & 1.210 & 1.066 & 1.375 & 0.003 \\
\hline Triglycerides & 1.000 & 1.000 & 1.000 & 0.943 \\
\hline Total Cholesterol & 1.001 & 1.000 & 1.003 & 0.086 \\
\hline BMI & 0.998 & 0.987 & 1.008 & 0.664 \\
\hline Diabetes duration (years) & 1.008 & 1.002 & 1.015 & 0.13 \\
\hline \multicolumn{5}{|l|}{ Target Blood Pressure } \\
\hline & \multirow[t]{2}{*}{$\mathrm{PR}$} & \multicolumn{2}{|l|}{$95 \% \mathrm{Cl}$} & \multirow[t]{2}{*}{$P$} \\
\hline & & Lower & Upper & \\
\hline Skin color (black) & 1.147 & 0.951 & 1.383 & 0.152 \\
\hline Age & 1.013 & 1.005 & 1.020 & 0.001 \\
\hline Gender (female) & 0.960 & 0.829 & 1.111 & 0.581 \\
\hline Medications (3 or more) & 1.217 & 1.047 & 1.414 & 0.011 \\
\hline BMI & 1.011 & 0.999 & 1.024 & 0.075 \\
\hline
\end{tabular}

PR: Prevalence ratio, BMl: body mass index, Medications: use of three or more anti-hypertensive medications. 
Table 3

Clinical and laboratory characteristics of type 2 diabetes patients according to gender and stratified by achieving or not $\mathrm{HbA} 1 \mathrm{c}$ target values.

\begin{tabular}{|c|c|c|c|c|c|c|}
\hline & \multicolumn{2}{|l|}{ Men } & \multirow{2}{*}{$\begin{array}{l}\mathrm{P} \text { - } \\
\text { value }\end{array}$} & \multicolumn{2}{|l|}{ Women } & \multirow{2}{*}{$\begin{array}{l}\mathrm{P} \text { - } \\
\text { value }\end{array}$} \\
\hline & $\begin{array}{l}\text { Achieved } \\
(\mathrm{N}=98)\end{array}$ & $\begin{array}{l}\text { Not } \\
\text { Achieved } \\
(\mathrm{N}=130)\end{array}$ & & $\begin{array}{l}\text { Achieved } \\
(\mathrm{N}=101)\end{array}$ & $\begin{array}{l}\text { Not } \\
\text { Achieved } \\
(\mathrm{N}=273)\end{array}$ & \\
\hline Age (years) & $66 \pm 10$ & $62 \pm 11$ & 0.009 & $65 \pm 10$ & $62 \pm 10$ & 0.008 \\
\hline White & $90(92)$ & $112(86)$ & 0.260 & $92(91)$ & $224(82)$ & 0.047 \\
\hline Smokers & $11(11)$ & $14(11)$ & 0.999 & $7(7)$ & $25(9)$ & 0.783 \\
\hline $\mathrm{BMI}\left(\mathrm{kg} / \mathrm{m}^{2}\right)$ & $29 \pm 4$ & $30 \pm 5$ & 0.209 & $31 \pm 6$ & $32 \pm 5$ & 0.653 \\
\hline $\begin{array}{l}\text { Diabetes duration } \\
\text { (years) }\end{array}$ & $\begin{array}{l}17.4 \pm \\
10.6\end{array}$ & $16.7 \pm 9$ & 0.811 & $15 \pm 9$ & $18.2 \pm 9.3$ & 0.002 \\
\hline Insulin use & $54(55)$ & $101(78)$ & $\dot{0} 001$ & $48(48)$ & $213(78)$ & $<.001$ \\
\hline $\mathrm{SBP}(\mathrm{mmHg})$ & $134 \pm 18$ & $133 \pm 19$ & 0.559 & $138 \pm 21$ & $137 \pm 21$ & 0.630 \\
\hline $\mathrm{DBP}(\mathrm{mmHg})$ & $78 \pm 10$ & $78 \pm 11$ & 0.941 & $80 \pm 12$ & $79 \pm 12$ & 0.492 \\
\hline HbA1c (\%) & $\begin{array}{l}6.7(6.1- \\
7.3)\end{array}$ & $\begin{array}{l}8.9(7.8- \\
9.8)\end{array}$ & $\begin{array}{l}\text { by } \\
\text { design }\end{array}$ & $\begin{array}{l}6.7(6.3- \\
7.4)\end{array}$ & $9(8-10.3)$ & $\begin{array}{l}\text { by } \\
\text { design }\end{array}$ \\
\hline $\begin{array}{l}\text { Fasting plasma glucose } \\
\text { (mg/dL) }\end{array}$ & $120 \pm 43$ & $176 \pm 70$ & $<.001$ & $127 \pm 42$ & $177 \pm 83$ & $<.001$ \\
\hline $\begin{array}{l}\text { Total Cholesterol } \\
\text { (mg/dL) }\end{array}$ & $149 \pm 36$ & $163 \pm 45$ & 0.013 & $176 \pm 47$ & $177 \pm 41$ & 0.827 \\
\hline Triglycerides $(\mathrm{mg} / \mathrm{dL})$ & $\begin{array}{l}120(82- \\
174)\end{array}$ & $\begin{array}{l}136(90- \\
241)\end{array}$ & 0.073 & $\begin{array}{l}145(110- \\
196)\end{array}$ & $\begin{array}{l}153(104- \\
214)\end{array}$ & 0.558 \\
\hline
\end{tabular}

Data presented as mean \pm SD, median (IQR) or number of cases $(\%)$.

P-value was calculated by $\mathrm{X}^{2}$ or an independent sample t-test. BMI: body mass index; SBP: systolic blood pressure, DBP: diastolic blood pressure 
Table 4

Clinical and laboratory characteristics of type 2 diabetes patients according to blood pressure values.

\begin{tabular}{|c|c|c|c|}
\hline & \multicolumn{2}{|c|}{ Blood pressure target } & \multirow[t]{3}{*}{ P-value } \\
\hline & Achieved & Not Achieved & \\
\hline & $N=254$ & $N=348$ & \\
\hline Age & $61 \pm 11$ & $64 \pm 10$ & $<0.001$ \\
\hline Female & $157(62)$ & $215(62)$ & 0.999 \\
\hline White & $221(87)$ & $296(85)$ & 0.644 \\
\hline Smokers & $25(10)$ & $30(8.8)$ & 0.803 \\
\hline $\mathrm{BMI}\left(\mathrm{kg} / \mathrm{m}^{2}\right)$ & $30 \pm 6$ & $31 \pm 5$ & 0.123 \\
\hline Diabetes diagnosis (years) & $17 \pm 10$ & $17 \pm 9$ & 0.529 \\
\hline Insulin use & $165(65)$ & $251(72)$ & 0.084 \\
\hline $\mathrm{SBP}(\mathrm{mmHg})$ & $119 \pm 10$ & $148 \pm 16$ & by design \\
\hline $\mathrm{DBP}(\mathrm{mmHg})$ & $73 \pm 9$ & $83 \pm 11$ & by design \\
\hline $\mathrm{HbA1c}(\%)$ & $7.9(7-9.1)$ & $8.2(7-9.7)$ & 0.069 \\
\hline Fasting plasma glucose (mg/dL) & $137(102-183)$ & $144(112-196)$ & 0.054 \\
\hline Total Cholesterol (mg/dL) & $170 \pm 41$ & $172 \pm 74$ & 0.724 \\
\hline Triglycerides $(\mathrm{mg} / \mathrm{dL})$ & $142(98-212)$ & $144(99-203)$ & 0.582 \\
\hline Diabetes kidney disease & $104(41)$ & $233(67)$ & $<0.001$ \\
\hline Retinopathy & $112(44)$ & $171(49)$ & 0.345 \\
\hline Neuropathy & 99 (39) & $160(46)$ & 0.185 \\
\hline Macrovascular & $62(25)$ & $136(39)$ & $<0.001$ \\
\hline
\end{tabular}

Data presented as mean \pm SD, median (IQR) or number of cases $(\%)$.

P-value was calculated by $\mathrm{X}^{2}$ or an independent sample t-test. BMI: body mass index; SBP: systolic blood pressure, DBP: diastolic blood pressure.

\section{Discussion}


In the present study, $67 \%$ of the type 2 diabetes outpatients were above internationally recommended personalized $\mathrm{HbA} 1 \mathrm{c}$ levels and $58 \%$ were above target blood pressure levels. In contrast, in National Health and Nutrition Examination Survey (NHANES) cross-sectional data from 2013 to 2016, only 36\% of adults with diabetes did not meet individualized $\mathrm{A} 1 \mathrm{C}$ target levels, with a mean $\mathrm{HbA} 1 \mathrm{C}$ of $7.5 \%$, and just $30 \%$ did not achieve recommended blood pressure control (15). Nevertheless, similar to our findings, a meta-analysis of observational studies including North-America, Europe and Asia populations, demonstrates that $64 \%$ of type 2 patients did not meet HbA1c goals (16). Alike our findings, this metaanalysis describes that lower age, a higher proportion of females and non-Caucasians were all associated with a higher failure rate of achieving glycemic control.

While only $35 \%$ of diabetes-related health expenditure is spent in low- and middle-income countries, $87 \%$ of diabetes-related deaths occur there (1). Improved glycemic control in diabetes is associated with a lower risk of diabetes complications and reduced all-cause and cardiovascular mortality (17). In patients with type 2 diabetes, an $\mathrm{HbA} 1 \mathrm{c}$ level outside the target range was found to be the strongest predictor of stroke and acute myocardial infarction, the main cause of death in this population (18). Nevertheless, the $\mathrm{HbA1c}$ target should be individualized according to a number of factors, such as age, diabetes duration, comorbid conditions, life expectancy, risk of hypoglycemia, and patient adherence/preference. According to international consensus, an $\mathrm{HbA} 1 \mathrm{c}$ level $<7 \%$ is recommended for non-pregnant adults, while $7.0-8.0 \%$ is suggested for patients with co-morbidities or advanced age $(8,9,13,19)$. HbA1c targets of $7.5-8 \%$ were suggested in the most recent International Diabetes Federation clinical practice recommendations (1). Stricter $\mathrm{HbA} 1 \mathrm{c}$ goals, such as $6.5 \%$, are suggested for selected patients if they can be attained without significant hypoglycemia or other adverse effects (19). In our study, a less stringent HbA1c target of up to $8 \%$ was considered for patients with stage III DKD and ischemic heart disease (10). It has not been consistently shown that intensive glycemic control to $\mathrm{HbA} 1 \mathrm{c}$ levels $<7 \%$ reduces clinical microvascular and macrovascular events or death (20). Moreover, lowering HbA1c requires more anti-hyperglycemic medications at higher doses, which can lead to more adverse events $(21,22)$. Thus, personalizing glycemic goals in DM patients should include consideration of the benefits and hazards of pharmacotherapy.

In our cohort, patients not in the HbA1c target range were mostly women, younger and black and were more frequently insulin users. In NHANES sample, younger age (18-44 years), female sex, and nonwhite adults with diabetes, presented worse glycemic control over the study period (15). Manicardi et al. (23) observed that women were $33 \%$ more likely to have higher $\mathrm{HbA} 1 \mathrm{c}$ levels than men in a sample of type 1 diabetes patients (23). A study of type 2 diabetes patients found similar results, with women reaching $\mathrm{HbA1c}$ targets less often than men (24). It does not seem that our findings can be explained by differences in treatment or BMI between genders, since they were not significantly different. The access to the health service does not seem to be responsible either, since our sample is composed mostly of women and global diabetes-related health expenditure seems to be slightly higher in women than in men (1). Instead, these results could be related to a sex difference in carbohydrate metabolism during exercise, since women oxidize more lipids and less carbohydrates as a metabolic substrate than men (25). In addition, prior research has demonstrated sex differences in drug response regarding pharmacodynamic 
and pharmacokinetic factors (26). Although it is tempting to speculate that lifestyle elements, such as the amount and type of physical activity could also be involved, we did not collect such data.

Younger age has also been associated with worse glycemic control in diabetes in other studies (27-31). Individuals developing type 2 diabetes at an earlier age seem to represent a different phenotype that requires more aggressive interventions to achieve glycemic control (29). Rozenfeld at al. found older adult patients with type 2 diabetes to have improved adherence to antidiabetic medications (30). A 10\% increase in adherence to oral antidiabetic medications was associated with a $0.1 \%$ decrease in $\mathrm{HbA} 1 \mathrm{c}$, when controlled for baseline HbA1c and therapy regimen (30).

Another clinical characteristic that affected glycemic control included the use of insulin. Patients with type 2 diabetes who require insulin, alone or in combination with oral antidiabetic medications, consistently have higher $\mathrm{HbA} 1 \mathrm{c}$ values than those taking no medication or oral medications only $(16,28,32)$. Furthermore, sustained poor glycemic control was observed in patients with diabetes taking more medication of any kind (31). Insulin use could represent disease severity to some extent (27).

Regarding skin color, a sub-analysis of the Action to Control Cardiovascular Risk in Diabetes (ACCORD) trial showed that patients who failed to reach the $\mathrm{HbA} 1 \mathrm{c}$ target were more likely to be black and on insulin therapy, which agreed with our results (33). It is important to point out that some studies suggest that black subjects have higher HbA1c levels than whites, which could not be related to glycemic control itself, but rather to differences in HbA1c glycation patterns. Although our black patients presented higher $\mathrm{HbA1c}$, their fasting plasma glucose levels were similar. A meta-analysis that included non-diabetic subjects found that $\mathrm{HbA} 1 \mathrm{c}$ levels were around $4.7 \%$ higher in blacks than whites (34). These results are similar to those of previous studies in diabetic patients, which indicated a $0.65 \%$ higher $\mathrm{HbA} 1 \mathrm{c}$ level in African Americans than in non-Hispanic whites (35). Such ethnic disparities could be explained by genetic and/or environmental factors. One study has claimed that socioeconomic factors are the main cause of this disparity (36). However, other studies have reported that genetic variants may be responsible for increasing or reducing the enzyme activity in $\mathrm{HbA} 1 \mathrm{c}$ metabolism, which consequently affects $\mathrm{HbA1c}$ levels, possibly with distinct patterns in different races (37). Although we did not collect data on socioeconomic status in our cohort, this was probably not the major explanation for the discrepancy, since only black women had higher HbA1c.

Regarding blood pressure goals, $58 \%$ of the patients in our cohort did not meet the target levels, despite adjustment for cardiovascular risk status. These patients were older and had a higher prevalence of ischemic heart disease, stroke and DKD, which could reflect the difficulty of achieving the stricter goals required for these specific groups or that they indeed had a previous past of worse blood pressure control. In a 2014 cross-sectional analysis of patients in a Belgium hospital, Camara et al. (38) found that approximately $68 \%$ of type 2 diabetes patients had SBP levels $>130 \mathrm{mmHg}(38)$. In our study, BP control was defined according to recent ADA and ESC/AHA/ACC guidelines, with desirable BP values < $140 / 90 \mathrm{mmHg}$, except for patients with high cardiovascular risk and DKD, when $<130 / 80 \mathrm{mmHg}$ was recommended $(39,40)$. Although optimal BP targets are still under discussion, it has been demonstrated 
that lowering BP levels in hypertensive type 2 diabetes patients is definitely beneficial $(18,41)$. A metaanalysis found a significantly lower risk of mortality, cardiovascular events, coronary heart disease, and heart failure in DM patients whose baseline SBP was $\geq 140 \mathrm{mmHg}$ and then reduced $10 \mathrm{mmHg}$ with treatment (41). Additionally, lowering a baseline SBP $\geq 130 \mathrm{mmHg}$ by $10 \mathrm{mmHg}$ was associated with a lower risk of stroke, albuminuria and retinopathy (36). In patients with DKD, the recommended goals of $\mathrm{SBP}<130 \mathrm{mmHg}$ and DBP $<80 \mathrm{mmHg}$ helped prevent macrovascular and microvascular outcomes $(42,43)$. Accordingly, we defined our BP cut-off points based on these findings, requiring stricter values for patients with DKD.

In our cohort, the patients who did not achieve the BP control goals were older. This finding could be explained by certain theories. First, the definition of hypertension in the general population is the same for any age category. However, several important studies have claimed that SBP and, mainly, DBP goals should not be the same for people over 75 years of age $(44,45)$. In this subset of patients, SBP and DBP targets of $<150 \mathrm{mmHg}$ and $<90 \mathrm{mmHg}$, respectively, are recommended. According to the Brazilian Cardiology Society, it would be safer to keep the SBP goal around $<150 \mathrm{mmHg}$ rather than $140 \mathrm{mmHg}$ in older adults to avoid the consequences of hypotension $(39,40,46)$. However, since the benefits of more restricted targets are undeniable, even for older people, we did not make distinctions for advanced age (45). The ADVANCE study (Action in Diabetes and Vascular disease: Preterax and Diamicron-MR Controlled Evaluation) investigated older hypertensive type 2 diabetes patients in a specific sub-analysis (42). The authors emphasized that adequate hypertension treatment in individuals $>65$ years of age (i.e. reducing SBP by approximately $5.6 \mathrm{mmHg}$ in a sample with a baseline mean BP of $145 / 81 \mathrm{mmHg}$ ) led to a corresponding reduction in the risk of mortality and major macrovascular and microvascular complications, mainly albuminuria (42). However, this study may have analyzed a sample of healthier diabetic patients, since the ADVANCE study did not include type 2 diabetes patients on long-term insulin therapy (47). We decided not to adapt the BP goals in our cohort according to age.

Regarding diabetic chronic complications in our population, it was observed that $56 \%$ had DKD, $47 \%$ had retinopathy, $43 \%$ had peripheral neuropathy, and $33 \%$ had macrovascular disease. These numbers seem to be on the high end of the most recent International Diabetes Federation data, in which the reported prevalence of diabetic peripheral neuropathy ranged from $16-66 \%$ and the prevalence of any retinopathy was $35 \%$ (1). Likewise, there was a high prevalence of DKD and cardiovascular disease in our sample, since global statistics show ranges of $12-55 \%$ and $12-31.7 \%$, respectively, for these complications $(1,48,49)$. Patients at the target $\mathrm{HbA1c}$ levels had a higher prevalence of macrovascular disease. The possible explanations are that this group was older and that the adopted $\mathrm{HbA} 1 \mathrm{c}$ target for patients with previous ischemic heart disease or stroke were higher, facilitating this sub-sample to achieve HbA1c target. In addition, patients with macrovascular disease might have more intense health care attention due to these higher risk conditions. On the other hand, patients in the uncontrolled blood pressure group had a higher prevalence of ischemic heart disease or stroke and DKD. These results could be explained by the fact that poor lifelong blood pressure control resulted in kidney damage, but also that impaired kidney function indeed interferes with blood pressure control. 
Limitations: Since we evaluated cross-sectional data, the results are snapshots of diabetes care during the survey periods. Our study was conducted in a specialized tertiary health center involving patients with a predictable worse glycemic and blood pressure control, since those with good results are discharged to primary care units. Furthermore, for the same reason, the prevalence of chronic complications is overrepresented. Therefore, it reflects a specific setting. An additional limitation was that data on physical exercise and socioeconomic profile were not collected, and this limits the interpretation of the results regarding the ethnic and gender differences found in the analysis. More distinct mechanisms and associations still remain to be clarified.

Strengths: Data was collected from the expressive number of 602 outpatients, for about 5 years, in a number of well-characterized categories that involved diagnosis and monitoring of diabetes and its complications, following a comprehensive and standardized protocol. Thus, our large sample was able to identify specialized care figures and comorbidity risks with great reliability. There have been few studies on the profile of diabetic patients that involved so many variables in our geographic area.

\section{Conclusions}

In conclusion, since more than half of the type 2 diabetes patients in this Brazilian cohort were not at target glycemic and blood pressure levels, there is a major call to overcome therapeutic inertia and treat to target for an individual patient. Our study confirmed that certain predictive factors can influence this setting, and focused strategies to help patients with these clinical characteristics are essential to better achieve glycemic targets and reduce the burden of diabetes related co-morbidities.

\section{Declarations}

\section{Ethics approval and consent to participate}

This study was approved by the Institutional Ethics Committee (GPPG\# 140073).

\section{Consent for publication}

Not applicable.

\section{Availability of data and materials}

The datasets used and/or analysed during the current study are available from the corresponding author on reasonable request.

\section{Competing interests}

The authors declare no conflict of interest.

\section{Funding}


This study was supported by grants from the Fundação de Amparo à Pesquisa do Estado do Rio Grande do Sul (FAPERGS), the Conselho Nacional de Desenvolvimento Científico e Tecnológico (CNPq), the Hospital de Clínicas de Porto Alegre Fundo de Incentivo à Pesquisa e Eventos (FIPE) and the Coordenação de Aperfeiçoamento de Pessoal de Nível Superior (CAPES) (number 16/2551-0000-476-5).

\section{Authors' contributions}

CBF, SC, LB and CKD acquired the data and drafted the manuscript. FS and TZ interpreted the data and reviewed the manuscript. SPS designed the study, interpreted the data and reviewed the manuscript. All authors read and approved the final manuscript.

\section{Acknowledgements}

Not applicable.

\section{References}

1. Williams R, Colagiuri S, Almutairi R, Montoya PA et al. IDF Diabetes Atlas: Ninth edition 2019. International Diabetes Federation, 2019; 2019.

2. Malerbi DA, Franco LJ. Multicenter study of the prevalence of diabetes mellitus and impaired glucose tolerance in the urban Brazilian population aged 30-69 yr. Diabetes Care. 1992 Nov 1;15(11):150916.

3. Schmidt MI, Duncan BB, e Silva GA, Menezes AM, Monteiro CA, Barreto SM, et al. Chronic noncommunicable diseases in Brazil: burden and current challenges. Lancet. 2011 Jun 4;377(9781):1949-61.

4. Schmidt MI, Hoffmann JF, de Fátima Sander Diniz M, Lotufo PA, Griep RH, Bensenor IM, et al. High prevalence of diabetes and intermediate hyperglycemia - The Brazilian Longitudinal Study of Adult Health (ELSA-Brasil). Diabetol Metab Syndr. 2014 Dec 18;6(1):123.

5. American Diabetes Association. 10. Cardiovascular Disease and Risk Management: Standards of Medical Care in Diabetes-2020. Diabetes Care 2020 Jan; 43 (Supplement 1): S111-S134

6. Barrett EJ, Liu Z, Khamaisi M, King GL, Klein R, Klein BEK, et al. Diabetic Microvascular Disease: An Endocrine Society Scientific Statement. J Clin Endocrinol Metab. 2017 Dec 1;102(12):4343-410.

7. Zagkotsis G, Markou M, Paschou E, Papanikolaou P, Sabanis N. Preventing the development and progression of diabetic kidney disease: Where do we stand? Diabetes Metab Syndr Clin Res Rev. 2018 Jul;12(4):585-90.

8. American Diabetes Association AD. 6. Glycemic Targets: Standards of Medical Care in Diabetes2020. Diabetes Care 2020 Jan; 43(Supplement 1): S66-S76.

9. Garber AJ, Abrahamson MJ, Barzilay JI, Blonde L, Bloomgarden ZT, Bush MA, et al. Consensus Statement by the American Association of Clinical Endocrinologists and American College of 
Endocrinology on the Comprehensive Type 2 Diabetes Management Algorithm - 2017 Executive Summary. Endocr Pract. 2017 Feb;23(2):207-38.

10. International Diabetes Federation (IDF). Global Diabetes Plan 2011-2021. Brussels; 2012.

11. Levey AS, Stevens LA, Schmid CH, Zhang YL, Castro AF, Feldman $\mathrm{HI}$, et al. A new equation to estimate glomerular filtration rate. Ann Intern Med. 2009 May 5;150(9):604-12.

12. Incerti J, Zelmanovitz T, Camargo JL, Gross JL, de Azevedo MJ. Evaluation of tests for microalbuminuria screening in patients with diabetes. Nephrol Dial Transplant. $2005 \mathrm{Nov}$ 1;20(11):2402-7.

13. Davies MJ, D'Alessio DA, Fradkin J, Kernan WN, Mathieu C, Mingrone G, et al. Management of Hyperglycemia in Type 2 Diabetes, 2018. A Consensus Report by the American Diabetes Association (ADA) and the European Association for the Study of Diabetes (EASD). Diabetes Care. 2018 Dec;41(12):2669-701.

14. Piepoli MF, Hoes AW, Agewall S, Albus C, Brotons C, Catapano AL, et al. 2016 European Guidelines on cardiovascular disease prevention in clinical practice. Eur Heart J. 2016 Aug 1;37(29):2315-81.

15. Kazemian P, Shebl FM, McCann N, Walensky RP, Wexler DJ.. Evaluation of the cascade of diabetes care in the United States, 2005-2016. JAMA Intern Med. 12 August 2019 [Epub ahead of print] DOI: 10.1001/jamainternmed.2019.2396

16. Mannucci E, Monami M, Dicembrini I, Piselli A, Porta M. Achieving HbA1c targets in clinical trials and in the real world: a systematic review and meta-analysis. J Endocrinol Invest. 2014 May 4;37(5):47795.

17. Orsi E, Bonora E, Solini A, Fondelli C, Trevisan R, Vedovato M, Cavalot F, Zerbini G, Morano S, Nicolucci A, Penno G, Pugliese G. Association between On-Treatment Haemoglobin A1c and AllCause Mortality in Individuals with Type 2 Diabetes: Importance of Personalized Goals and Type of Anti-Hyperglycaemic Treatment. J Clin Med. 2020 Jan 17;9(1)

18. Rawshani A, Rawshani A, Franzén S, Sattar N, Eliasson B, Svensson A-M, et al. Risk Factors, Mortality, and Cardiovascular Outcomes in Patients with Type 2 Diabetes. N Engl J Med. 2018 Aug 16;379(7):633-44.

19. Riddle MC, Gerstein HC, Holman RR, Inzucchi SE, Zinman B, Zoungas S, et al. A1C Targets Should Be Personalized to Maximize Benefits While Limiting Risks. Diabetes Care. 2018 Jun 21;41(6):1121-4.

20. Qaseem A, Wilt TJ, Kansagara D, Horwitch C, Barry MJ, Forciea MA, et al. Hemoglobin A 1c Targets for Glycemic Control With Pharmacologic Therapy for Nonpregnant Adults With Type 2 Diabetes Mellitus: A Guidance Statement Update From the American College of Physicians. Ann Intern Med. 2018 Apr 17;168(8):569.

21. Group TA to CCR in DS. Effects of Intensive Glucose Lowering in Type 2 Diabetes. N Engl J Med. 2008 Jun 12;358(24):2545-59.

22. Beddhu S, Chertow GM, Cheung AK, Cushman WC, Rahman M, Greene T, et al. Influence of Baseline Diastolic Blood Pressure on Effects of Intensive Compared With Standard Blood Pressure Control. Circulation. 2018 Jan 9;137(2):134-43. 
23. Manicardi V, Russo G, Napoli A, Torlone E, Li Volsi P, Giorda CB, et al. Gender-Disparities in Adults with Type 1 Diabetes: More Than a Quality of Care Issue. A Cross-Sectional Observational Study from the AMD Annals Initiative. Manzoli L, editor. PLoS One. 2016 Oct 3;11(10):e0162960.

24. Rossi MC, Cristofaro MR, Gentile S, Lucisano G, Manicardi V, Mulas MF, et al. Sex Disparities in the Quality of Diabetes Care: Biological and Cultural Factors May Play a Different Role for Different Outcomes: A cross-sectional observational study from the AMD Annals initiative. Diabetes Care. 2013 Oct 1;36(10):3162-8.

25. Tarnopolsky MA, Ruby BC. Sex differences in carbohydrate metabolism. Curr Opin Clin Nutr Metab Care. 2001 Nov;4(6):521-6.

26. Franconi F, Seghieri G, Canu S, Straface E, Campesi I, Malorni W. Are the available experimental models of type 2 diabetes appropriate for a gender perspective? Pharmacol Res. 2008 Jan;57(1):618.

27. Lee SM, Song I, Suh D, Chang C, Suh DC. Treatment Costs and Factors Associated with Glycemic Control among Patients with Diabetes in the United Arab Emirates. J Obes Metab Syndr.2018 Dec;27(4):238-247

28. Benoit SR, Fleming R, Philis-Tsimikas A, and Ji M. Predictors of glycemic control among patients with type 2 diabetes: a longitudinal study. BMC Public Health 2005;5:36.

29. Nichols GA, Hillier TA, Javor K, and Brown JB. Predictors of glycemic control in insulin-using adults with type 2 diabetes. Diabetes Care 2000;23:273-7.

30. Rozenfeld Y, Hunt JS, Plauschinat $C$, and Wong KS. Oral antidiabetic medication adherence and glycemic control in managed care. Am J Manag Care 2008;14:71-5.

31. Fox KM, Gerber Pharmd RA, Bolinder B, Chen J, and Kumar S. Prevalence of inadequate glycemic control among patients with type 2 diabetes in the United Kingdom general practice research database: a series of retrospective analyses of data from 1998 through 2002. Clin Ther 2006;28:38895.

32. Juarez DT, Sentell T, Tokumaru S, Goo R, Davis JW, and Mau MM. Factors associated with poor glycemic control or wide glycemic variability among diabetes patients in Hawaii, 2006-2009. Prev Chronic Dis 2012;9:120065.

33. Drake TC, Hsu F-C, Hire D, Chen S-H, Cohen RM, McDuffie R, et al. Factors associated with failure to achieve a glycated haemoglobin target of. Diabetes, Obes Metab. 2016 Jan;18(1):92-5.

34. Cavagnolli G, Pimentel AL, Freitas PAC, Gross JL, Camargo JL. Effect of ethnicity on HbA1c levels in individuals without diabetes: Systematic review and meta-analysis. Ali R, editor. PLoS One. 2017 Feb 13;12(2):e0171315.

35. Kirk JK, D'Agostino RB, Bell RA, Passmore L V, Bonds DE, Karter AJ, et al. Disparities in HbA1c levels between African-American and non-Hispanic white adults with diabetes: a meta-analysis. Diabetes Care. 2006 Sep;29(9):2130-6.

36. Maruthur NM, Kao WHL, Clark JM, Brancati FL, Cheng C-Y, Pankow JS, et al. Does genetic ancestry explain higher values of glycated hemoglobin in African Americans? Diabetes. 2011 
Sep;60(9):2434-8.

37. Avemaria F, Carrera P, Lapolla A, Sartore G, Chilelli NC, Paleari R, et al. Possible role of fructosamine 3-kinase genotyping for the management of diabetic patients. Clin Chem Lab Med. 2015 Jan 1;53(9):1315-20.

38. Camara S, Bouenizabila E, Hermans MP, Ahn SA, Rousseau MF. Novel determinants preventing achievement of major cardiovascular targets in type 2 diabetes. Diabetes Metab Syndr. 2014;8(3):145-51.

39. Boer IH de, Bangalore S, Benetos A, Davis AM, Michos ED, Muntner P, et al. Diabetes and Hypertension: A Position Statement by the American Diabetes Association. Diabetes Care. 2017 Sep 1;40(9):1273-84.

40. Whelton PK, Carey RM, Aronow WS, Casey DE, Collins KJ, Dennison Himmelfarb C, et al. 2017 ACC/AHA/AAPA/ABC/ACPM/AGS/APhA/ASH/ASPC/NMA/PCNA Guideline for the Prevention, Detection, Evaluation, and Management of High Blood Pressure in Adults: Executive Summary: A Report of the American College of Cardiology/American Heart Association Task Force on Clinical Practice Guidelines. Hypertension. 2018 Jun;71(6):1269-324.

41. Emdin CA, Rahimi K, Neal B, Callender T, Perkovic V, Patel A. Blood Pressure Lowering in Type 2 Diabetes. JAMA. 2015 Feb 10;313(6):603.

42. Patel A, ADVANCE Collaborative Group, MacMahon S, Chalmers J, Neal B, Woodward M, et al. Effects of a fixed combination of perindopril and indapamide on macrovascular and microvascular outcomes in patients with type 2 diabetes mellitus (the ADVANCE trial): a randomised controlled trial. Lancet. 2007 Sep 8;370(9590):829-40.

43. Parving H-H, Lehnert H, Bröchner-Mortensen J, Gomis R, Andersen S, Arner P. The Effect of Irbesartan on the Development of Diabetic Nephropathy in Patients with Type 2 Diabetes. N Engl J Med. 2001 Sep 20;345(12):870-8.

44. Port S, Demer L, Jennrich R, Walter D, Garfinkel A. Systolic blood pressure and mortality. Lancet. 2000 Jan 15;355(9199):175-80.

45. Beckett NS, Peters R, Fletcher AE, Staessen JA, Liu L, Dumitrascu D, et al. Treatment of Hypertension in Patients 80 Years of Age or Older. N Engl J Med. 2008 May 6;358(18):1887-98.

46. Faludi A, Izar M, Saraiva J, Bianco H, Chacra A, Bertoluci M, et al. Diretriz brasileira baseada em evidências sobre prevenção de doenças cardiovasculares em pacientes com diabetes: posicionamento da Sociedade Brasileira de Diabetes (SBD), da Sociedade Brasileira de Cardiologia (SBC) e da Sociedade Brasileira de Endocrinologia e Metabologia (SBEM). Arq Bras Cardiol. 2017;109(6):1-31.

47. van Hateren KJJ, Landman GWD, Kleefstra N, Houweling ST, van der Meer K, Bilo HJG. Time for considering other blood pressure target values in elderly patients with type 2 diabetes? Int $\mathrm{J}$ Clin Pract. 2012 Feb;66(2):125-7.

48. Harding JL, Pavkov ME, Magliano DJ, Shaw JE, Gregg EW. Global trends in diabetes complications: a review of current evidence. Diabetologia. 2019 Jan 31;62(1):3-16. 
49. Persson F, Rossing P. Diagnosis of diabetic kidney disease: state of the art and future perspective. Kidney Int Suppl. 2018 Jan;8(1):2-7.

Figures

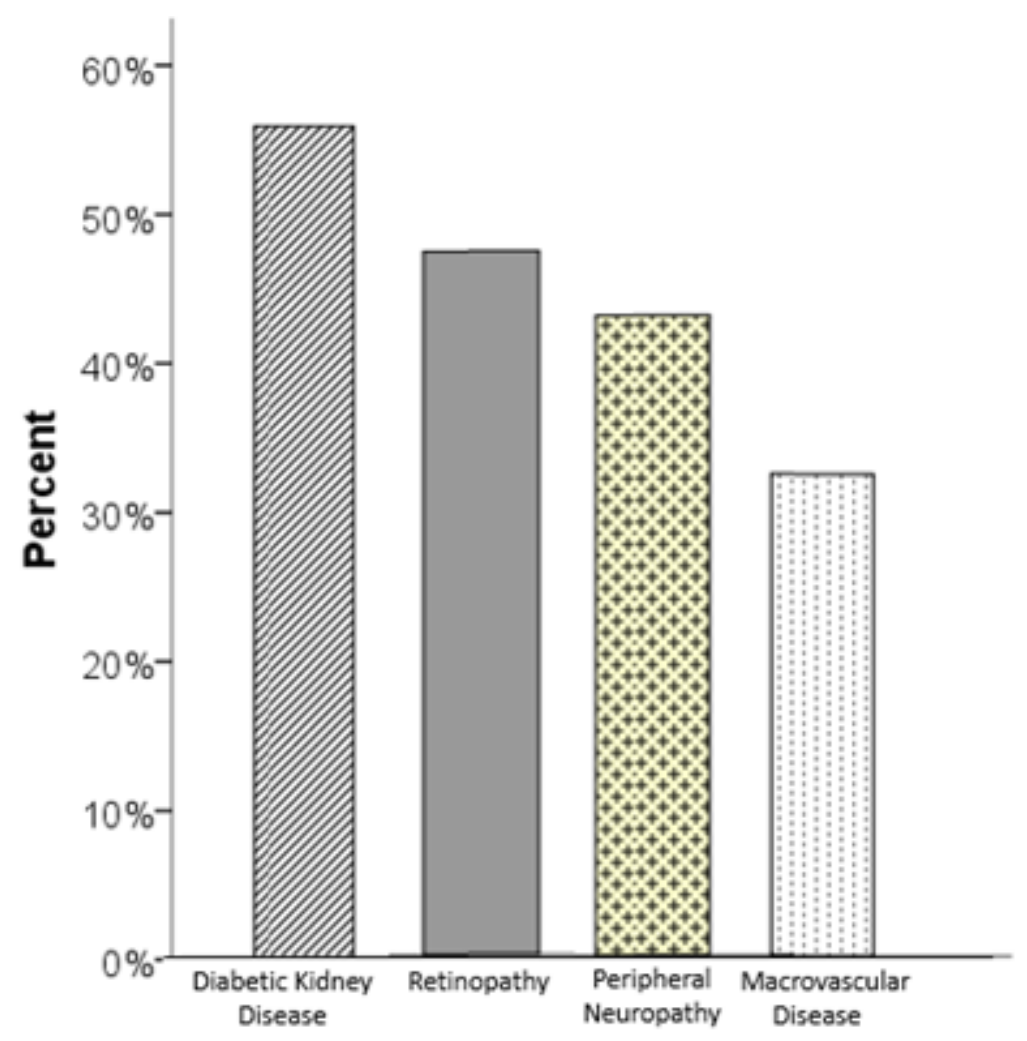

\section{Figure 1}

Prevalence of microvascular (diabetes kidney disease, diabetic retinopathy and neuropathy) and macrovascular complications in type 2 diabetes patients. 